\title{
Trabajo docente con padres y madres de familia, un recuento en la
}

\section{Educación Preescolar. México}

Teaching practice with fathers and mothers. A recount in Preschool Education. Mexico

\author{
Volumen 19, Número 1 \\ Enero-Abril \\ pp. 1-28
}

\section{Este número se publica el 1 de enero de 2019}

DOI: 10.15517/aie.v19i1.35169

Leticia Montaño Sánchez

Revista indizada en REDALYC, $\underline{\text { SCIELO }}$

Revista distribuida en las bases de datos:

LATINDEX, DOAJ, $\underline{\text { REDIB }}$ IRESIE, $\underline{\text { CLASE}}$, DIALNET, SHERPA/ROMEO, QUALIS-CAPES, MIAR

Revista registrada en los directorios:

ULRICH'S, REDIE, RINACE, OEI, MAESTROTECA, PREAL, CLACSO 


\section{Trabajo docente con padres y madres de familia, un recuento en la Educación Preescolar. México \\ Teaching practice with fathers and mothers. A recount in Preschool Education. Mexico}

\section{Leticia Montaño Sánchez ${ }^{1}$}

Resumen: Este ensayo presenta un panorama histórico analítico de momentos en la educación preescolar (México) donde la relación de docentes con padres y madres de familia es relevante para la organización y funcionamiento de los jardines de población infantil. A la vez, se revisan los planes de estudio para la formación inicial de docentes en este nivel educativo. Los análisis muestran procesos políticos, sociales y económicos que propiciaron el trabajo docente con padres y madres de familia. Se devela que la presencia de padres y madres en las escuelas obedece al interés de estos por brindar a sus hijas e hijos mejores condiciones para su quehacer escolar. Se concluye que el ejercicio de la profesión docente demanda el trabajo permanente con padres y madres, el cual se aprende en el ejercicio de la práctica y escasamente en la formación inicial. El artículo presenta algunas recomendaciones para el trabajo docente con madres y padres de familia.

Palabras clave: educación preescolar, formación de docentes de preescolar, trabajo docente, relación padres-escuela

Abstract: This essay resents a historical overview of preschool education in Mexico. Particularly, it refers to the moments when the relationship of teachers with parents has been relevant for the organization and operation in kindergartens. This study also reviews the syllabi of preschool preservice teacher education to confirm if the parent-teacher relations has been researched during this teacher training process. The analyses outlines major social and economic processes favoring the work of teachers with parents. It also discloses the presence of fathers and mothers in schools is due to their interest in providing their children with better conditions for their school work. A conclusion reached is that teacher's work with fathers and mothers offers them experience which is scarcely gained during the practicum. Consequently, this article presents some recommendations to strengthen their pre-service teacher education.

Keywords: pre-school education, pre-school teacher education, teaching practice, parent school relationship

\footnotetext{
1 Docente-investigador de la Escuela Nacional para Maestras de Jardines de Niños, México. Doctora en Ciencias, en la especialidad de Investigaciones Educativas por el Departamento de Investigaciones Educativas del Centro de Investigación y de Estudios Avanzados del Instituto Politécnico Nacional.
}

Dirección electrónica: ix chel30@hotmail.com

Ensayo recibido: 29 de marzo, 2018

Enviado a corrección: 31 de agosto, 2018

Aprobado: 29 de octubre, 2018 


\section{Introducción}

En México, la educación preescolar ${ }^{2}$ se caracteriza por ser un campo escasamente atendido por la investigación educativa (Galván, Quintanilla y Ramírez, 2003; Saucedo, Guzmán, Sandoval y Galaz, 2013; Zúñiga, 2002). La revisión de estudios sobre este nivel educativo realizada por Campos (2013) permite a la autora identificar tres líneas de trabajo de corte histórico. La primera, referida al proceso educativo nacional, donde se distinguen algunos rasgos de la educación preescolar. Estos escritos se aprecian en las obras de Bazant (2002), Civera (1999), Larroyo (1947), Meneses (1986) y Zea (1956). La segunda línea, refiere Campos (2013), recupera investigaciones, artículos y ponencias sobre la historia de este nivel educativo, entre los trabajos la autora destaca, los realizados por Larrauri (1989), Manríquez y Larios (2004), Molina (2002), Reyes y Saleh (2006), Sordo (1980), Venegas e Ibarra (2005) y por la Secretaría de Educación de Yucatán (2003). El tercer conjunto de escritos alude a obras biográficas, monografías de la época e investigaciones históricas sobre la formación de maestros y maestras, así como de escuelas primarias con menciones sobre educación preescolar. En este conjunto de escritos, señala Campos (2013), se encuentran las obras de Bazant (2003 y 2009), González (2010) y Reyes (1948).

De manera particular, en el campo de estudio sobre las relaciones escuela familia, García (2002) advierte que el estudio de la participación de padres y madres ${ }^{3}$ de los menores que asisten a la educación preescolar "no es asunto sencillo" de resolver en términos históricos.

[...] Sus voces no son aprehensibles con facilidad; como actores o sujetos sociales ocupan un lugar marginal dentro de la historiografía, como tema y problema histórico son de esos grandes silencios de la historia cuya presencia apenas empieza a ser develada. (p.39)

Por otra parte, Mercado (1985) en sus estudios de corte etnográfico identifica que tanto padres y madres de quienes están en edad de cursar la educación básica, así como otros

\footnotetext{
${ }^{2}$ Este nivel educativo comprende tres grados y precede a la educación primaria. Al primer grado asiste alumnado de tres años de edad cumplidos; al segundo, niños y niñas de cuatro años y al tercero, alumnado de cinco años. En México, este nivel educativo forma parte de la educación básica junto con la primaria (seis grados) y la secundaria (tres grados).

${ }^{3}$ El estudio no centra su mirada y discusiones en torno a la reconfiguración de las familias y a la presencia de quienes fungen como cuidadores o tutores de los menores.
} 
habitantes locales suelen categorizarse como la homogénea y difusa comunidad, pues su presencia es poco visible en la vida escolar cotidiana. En el ámbito de la formación de futuras personas docentes, Galván (1998, p. 181) destaca que "existe un vacío para aproximarse a las valoraciones que los padres tienen respecto al trabajo en el salón y otro más para mostrar las habilidades docentes encaminadas a trabajar individual y colectivamente con ellos". En esta línea que alude a la formación docente, Mercado y Luna (2013), Mercado y Montaño (2015) también enfatizan la ausencia de procesos formativos vinculados al trabajo docente con padres y madres del alumnado tanto en la formación inicial como de docentes en servicio. En otras latitudes, Rivas reporta que indagaciones realizadas por Nalls, Mullis, Cornille, Mullis y Jeter (2011) han puesto de manifiesto que las personas que ejercen como maestros y maestras en los diversos niveles del sistema educativo obligatorio español, "no suelen tener estrategias efectivas para identificar a las familias con las que va a ser complejo colaborar, ni tampoco tienen posibilidad de saber cómo trabajar de forma efectiva con las que demandan modos distintos de implicación" (2014, p.158).

Estos estudios evidencian la necesidad de discutir y revisar el tema de las relaciones entre los y las docentes con las familias a la luz de las construcciones sociohistóricas que enmarcan el ejercicio cotidiano de los maestros, estudios que, a su vez, enfrentan la dificultad de rastrear en documentos las voces de padres y madres o bien, del trabajo emprendido por docentes con la comunidad.

Este escrito tiene como objetivo presentar una revisión en la historia de la educación preescolar para identificar momentos que evidencien el trabajo de los y las docentes con padres y madres, así como analizar menciones en los planes de estudio para la formación inicial del futuro profesorado respecto al trabajo con padres y madres de familia. Interesa responder a las preguntas de investigación: ¿el estudio de las relaciones de trabajo de la persona docente con padres y madres de familia ha estado presente en la formación inicial de quienes atienden la educación preescolar en México? ${ }^{4}$

Esta pregunta surgió en el marco de una investigación etnográfica más amplia orientada al estudio de las relaciones de trabajo de docentes de jardines de niños con padres o madres de familia, el trabajo de campo se desarrolló durante tres ciclos escolares (20112012, 2012-2013 y 2013-2014) en dos jardines de niños ubicados en una entidad federativa

\footnotetext{
${ }^{4}$ En este estudio, la etnografía fue la perspectiva metodológica que orientó el trabajo de campo y los ejercicios analíticos a partir de recuperar elementos de la perspectiva metodológica tributaria de las contribuciones de Geertz (1987), Bertely (2000) y Rockwell (2009).
} 
cercana a la Ciudad de México. En este esfuerzo investigativo surgió la necesidad de indagar si en los planes de estudio para la formación docente se abordaban contenidos referentes al trabajo con padres y madres de familia. En este sentido, el interés se centró en "reconstruir tramas de significado" donde el análisis documental constituyó una fuente de información "para iluminar mejor algunos de los procesos educativos", identificados en el trabajo analítico del material empírico (Rockwell, 2009, p. 156).

Para dar respuesta a la pregunta de investigación se partió del análisis documental en búsqueda de voces distantes en el tiempo que permitieran develar sentidos en torno al tema de las relaciones escuela familia o concretamente de las relaciones de docentes con padres y madres de familia. El ejercicio de análisis documental partió de buscar, identificar, reunir, seleccionar y analizar datos sobre el tema de interés presentes en documentos oficiales y no oficiales que, sin ser su objeto de estudio o materia de trabajo, dieran cuenta de procesos o menciones en torno a dos ejes: las relaciones de docentes de educación preescolar con integrantes de la comunidad y procesos para la formación docente en el ámbito del trabajo con padres o madres de familia. El análisis documental también permitió recuperar voces procedentes de fuentes primarias y secundarias documentadas en investigaciones etnográficas y de corte sociológico. El proceso para la sistematización de los datos partió de la elaboración de cuadros de contenido y la estructuración analítica por ejes.

Así, en el presente artículo se trabajan dos ejes con el fin de destacar la función social del profesorado presente desde el origen de las escuelas para párvulos y el punto de quiebre que representó la formación de licenciados y licenciadas en educación preescolar, en el marco de políticas educativas orientadas a propiciar la participación de padres y madres bajo la regulación de la escuela. En esta lógica para la argumentación, en el escrito se advierte, que el trabajo de los y las docentes con padres y madres de familia se expresa según las necesidades políticas, económicas, sociales y educativas del país. Paralelamente, se alude a los planes de estudio para la formación inicial de docentes y la atención se centra en identificar menciones sobre el trabajo con padres y madres a fin de analizar el lugar que ocupa en dicha formación.

Es importante destacar que la educación preescolar en México se ha caracterizado por ser uno de los niveles educativos atendido predominantemente por mujeres. El informe de docentes en México (INEE, 2014, p. 29) refiere que "en educación preescolar, independientemente del sostenimiento, 24 de cada 25 docentes en escuelas generales son 
mujeres; esta proporción disminuye en los preescolares indígenas (87.4\%) y en los cursos comunitarios (72.6\%)". En el presente escrito se parte de reconocer la presencia mayoritaria de mujeres que ejercen como docentes de estudiantes que cursan la educación preescolar, a quienes se alude de manera indistinta como educadoras, maestras, profesoras o docentes. También, es necesario señalar que, en México, el diseño y operación de los planes y programas de estudio para la Educación Normal son facultad del gobierno federal y son de observancia nacional.

\section{De la educación preescolar: sus orígenes y la función social con madres de familia}

La educación preescolar en México se caracteriza por ser uno de los niveles educativos más desatendidos por el Gobierno Federal para la asignación de presupuesto y diseño de políticas educativas orientadas a incrementar su cobertura a nivel nacional. Los orígenes de la educación preescolar en este país se remontan a las escuelas de párvulos en 1880, que atendían a niños y niñas entre tres y cinco años de edad. ${ }^{5}$ Estas escuelas aparecieron junto con la incorporación de la mujer al ámbito laboral y surgieron para la población de menores recursos económicos (Galván, 2002). En esa época, las escuelas eran consideradas como instituciones de carácter "filantrópico o asistencial-social", (Mondragón, 2001, p.14) y se concebía que la educación de los párvulos debiera ser dirigida por mujeres. En este caso, las profesoras realizaban trabajos como los siguientes:

[...] agricultura, siembra de semillas y observación de sus modificaciones, canto coral, explicación del texto de las canciones, cultivo del lenguaje, sustantivos concretos y adjetivos, conocimiento de las letras, principio de lecciones de cosas, lecciones orales. También generalidades sobre el interior del cuerpo humano, el sol, el día, la noche, la luna, las estrellas, instrucción cívica, los abuelos, los hermanos, los condiscípulos, la amistad, el trabajo, historia universal, conferencias familiares sobre hechos más notables, actividades que se daban casi sin la intención del niño. (Mondragón, 2001, p. 41)

\footnotetext{
${ }^{5}$ Se tienen registros de que en 1883 surgieron las primeras escuelas de párvulos, una de ellas en Veracruz, fundada por Enrique Laubscher y otra en el Distrito Federal, dirigida por el maestro Manuel Cervantes Imaz (SEP, 1990).
} 
Las actividades documentadas por Mondragón (2001) permiten apreciar que la escuela de párvulos fungía como una preparación para la escuela primaria, el juego fue sustituido por "el estudio". Las conferencias familiares implicaban pláticas de las madres "sobre hechos notables" que, en palabras de Campos (2013), consistían en intervenciones de las madres o educadoras para satisfacer necesidades intelectuales y morales de la población analizada. La educación parvularia estuvo fuertemente asociada a la figura materna y a los aprendizajes en el hogar.

En 1902 se inició una etapa de reorganización de las escuelas de párvulos y la mejora en la formación de profesionales que atendían a los párvulos, maestras como Estefanía Castañeda, Laura Méndez de Cuenca, Rosaura Zapata, Elena Zapata y Bertha Von Glümer, entre otras, fueron enviadas en distintas ocasiones durante la primera década del siglo XX a Estados Unidos y Europa para conocer los aspectos pedagógicos y organizativos del kindergarten, así como de la formación de docentes. En 1908 se creó la carrera de Educadora de Párvulos con un plan de estudios presentado por Bertha Von Glümer e inspirado en las aportaciones de Fröbel. De igual forma, se reformó el sentido de la educación en los entonces denominados Kindergarten, se buscó hacer de estos, un hogar "no en el sentido asistencialista del antiguo asilo u orfanato sino por el ambiente de amor, tranquilidad y paciencia que éstas primeras educadoras consideraban inherente a la madre y al hogar" (Campos, 2013, p. 102).

En 1916 se replanteó la formación de las educadoras con aportaciones froebelianas y se abrió un espacio para la observación en los kindergarten. Entre las materias específicas para la formación figuraban estudios de las obras de Fröebel: Dones y ocupaciones, Cuentos en el Kindergarten, Juegos de la madre, Métodos y programas, Trabajos manuales en el kindergarten, Acompañamiento en el armonio o piano, ejercicios físicos y Observación en el kindergarten. La observación en las escuelas se planteó como un espacio para aprender sobre los comportamientos de niños y niñas, y de las técnicas que empleaban las maestras para el trabajo con los menores.

En las escuelas se recuperó el planteamiento de Fröebel en cuanto a mirar el juego como la base para la educación de la niñez. Campos (2013) documenta que bajo esta visión:

[...] se erradicó el uso de la pizarra, la enseñanza de la lectura y la escritura, de contar y a sumar para dejarlo para después de los seis años y en la escuela correspondiente.

En el kindergarten se iría a jugar, juegos libres, juegos en círculo, con los Juegos de la 
Madre de Fröebel, pues de esa manera no solo aprendería el párvulo, sino también la jardinera que atenta, estudiaría al niño en su juego para conocerlo en toda su intimidad. (p. 92)

En 1917, los kindergarten fueron suprimidos del presupuesto de la Secretaría de Educación e incorporados a los Ayuntamientos, algunos otros localizados en municipalidades al interior del país fueron clausurados (Zapata, 1946). Retirar el presupuesto a estas escuelas implicó contar con la cooperación de padres y madres de familia quienes mediante sus aportaciones económicas y en especie mantuvieron en operación principalmente los kindergarten en la capital del país (SEP, 1990). Esta situación prevaleció por cinco años. En 1921, las escuelas que dependían de los Ayuntamientos pasaron a la Federación y un año más tarde (1922) se publicó el Reglamento Interior para la operación de estas escuelas y el programa de trabajo. Los kindergarten fueron considerados una transición entre la vida del hogar y la escolar; comprendió actividades como "observación de la naturaleza, juegos y cantos, dones y ocupaciones adecuadas al medio, recitaciones y dramatizaciones, dibujo, cultivo de plantas y cuidado de animales domésticos" (Mondragón, 2001, p.64). Se rechazó el sistema de disciplina escolar que mantuviera a los párvulos como seres pasivos, se buscó educar en la libertad, los derechos del educando, en la verdad, la belleza, el bien y la vida social (SEP, 1990).

En este contexto, durante el periodo de José Vasconcelos como Secretario de Educación Pública (12 de octubre de 1921 al 2 de julio de 1924) se impulsó la formación de docentes mediante cursos de verano.

[...] se logró concentrar a 212 maestras tituladas que tomaban 5 horas de clases por semana durante tres meses, aunada a la observación y práctica en los Jardines y Hogares Infantiles de la ciudad de México y estados limítrofes. Estos cursos se llevaron a cabo en forma contínua por un lapso de siete años más, ya que fueron suspendidos posteriormente por falta de locales apropiados y sustituídos por cursos por correspondencia con las mismas finalidades. (SEP, 1990, p.65) (Sic)

En la cita, destaca un componente en la formación de las maestras en servicio: la observación y práctica en jardines y Hogares Infantiles, reconocidas estas instituciones para la atención educativa a menores de tres a seis años de edad. La formación en la práctica 
respondió a la necesidad de formar a las docentes que ejercían como tales, sin la preparación específica para el nivel educativo naciente. En el periodo de 1924 a 1928, las discusiones giraron en torno al fortalecimiento de la carrera para ejercer como docente en escuelas para párvulos, en el sentido de tener más formalidad y propiciar en la formación múltiples experiencias mediante la convivencia diaria con preescolares. En ese entonces, la carrera se estudiaba en cinco años posteriores a la primaria elemental: tres de secundaria y dos de profesional.

En cuanto al personal docente en servicio, Estefanía Castañeda promovió que en la Facultad de Altos Estudios de la Universidad Autónoma de México, se ofrecieran cursos de posgrado, egresando de éstos, docentes con título universitario (SEP, 1990). Mejorar la formación del profesorado que atendían los jardines de niños encontró su vinculación con la necesidad de extender este servicio educativo a zonas alejadas de la capital del país, en 1926 existían tan solo 88 Kindergarten públicos.

Los esfuerzos por abrir espacio a un nivel educativo naciente encontraron su concreción en dos acciones principales; la primera, el fortalecimiento de la formación de docentes en servicio mediante el seminario sobre el jardín de niños y trabajo social impartido por Estefanía Castañeda a principios de la década de los treinta del siglo XX, dirigido a educadoras y trabajadoras sociales. Este seminario incluyó algunas materias de la formación inicial de docentes como Psicología Infantil, Literatura Infantil, Juegos, Música, Cantos; otras como Filosofía de la Educación, Técnicas del Kindergarten en el Ciclo Primario y Actividades Sociales y Domésticas fueron propias de este seminario (SEP, 1990, pp.83-84).

En el espacio destinado a Actividades Sociales y Domésticas, las maestras que asistían al seminario diseñaban y practicaban actividades sociales y del hogar con las madres de familia. Esta situación remite a las relaciones de trabajo y de cooperación principalmente entre educadoras y madres para desarrollar acciones orientadas a fundar jardines de niños en diversas ciudades del país, mantener en operación los existentes, trabajar la vinculación entre las actividades escolares y la vida en los hogares e impulsar la formación de docentes para este nivel educativo. Un ejemplo de ello fue el apoyo de docentes, padres y madres de familia para hacer posible el proyecto presentado en 1931 por la Secretaría de Educación Pública para la construcción de jardines de niños anexos a las Normales en los pueblos de Xocoyucan, Puebla; Actopan, Hidalgo; Erongarícuaro, Michocán; Tixtla, Guerrero y Oaxtepec, Morelos. Otro de los esfuerzos conjuntos del 
personal docente y la Sociedad de Madres fue la creación, en 1940, del Instituto de Información Educativa sobre Educación Preescolar (SEP, 1990).

De acuerdo con los datos presentados, se podría decir que en el periodo de 1917 a 1942 los jardines de niños vivieron un periodo de crecimiento por cuanto se logró consolidar el proyecto para establecer los jardines para infantes anexos a las Escuelas Normales Regionales y construirlos también al interior del país. En 1942 existían "510 jardines de niños entre oficiales, federales y particulares con un total de 15, 600 niños inscritos en jardines de niños del D.F. y 12,000 en los estados" (SEP, 1990, p. 96); situación que implicó a su vez la organización de diversos eventos con la cooperación de padres y madres de familia para obtener recursos económicos y materiales en apoyo a las escuelas; así como la contratación de asistentes preescolares no normalistas que atendían a esta población en zonas rurales. Bertely (1998, p.46) documenta que "misiones culturales de educadoras se trasladaron a los estados para proporcionar asesoría técnica a estas maestras hechas en la práctica". Además de visitar zonas marginadas para llevar a la población infantil actividades como cantos, juegos, teatro, entre otras. A este movimiento se le llamó Brigadas de Alegría (SEP, 1990).

Durante el periodo de 1943 a 1949 se impulsó la Campaña Nacional contra el Analfabetismo (1944 a 1946), se creó el Comité Federal del Programa de Construcción de Escuelas (1945) y se fundó el Instituto Nacional de Capacitación del Magisterio. En el ámbito de la educación preescolar, la campaña de alfabetización encontró apoyo en las educadoras y madres de familia, quienes continuaron en la organización de diversos eventos para reunir fondos y animar a la población para asistir a los cursos de alfabetización. La creación de 24 centros para este fin se encuentra documentada en diversos jardines de niños (SEP, 1990, p. 112).

La crisis económica de 1946-1947 en México generó que para la educación preescolar se asignara el presupuesto más bajo registrado en toda su historia. Ante la falta de recursos, las Sociedades de Madres de Familia con sus aportaciones económicas pagaron el sueldo del personal de los jardines de niños y contribuyeron en los gastos para el mejoramiento de los locales alquilados que funcionaban como escuelas, impulsaron la creación de escuelas en turnos vespertinos y jardines particulares. El apoyo de los padres de familia también se hizo presente en la alimentación de la niñez que acudía a las escuelas en zonas rurales y marginadas de las ciudades, mediante la participación de las Sociedades de Madres (SEP, 1990). 
A finales de la década de los cuarenta del siglo XX, en el texto Educación Preescolar. México 1880-1982, se documenta que el trabajo de las docentes fue más allá de los planteles, al crear la Comisión Nacional de Trabajo Social, que permitió a las educadoras intensificar "la labor social que desde años atrás venían desarrollando". En consonancia, la preparación de las educadoras en servicio contempló cursos para organizar la labor social con las madres de familia y demostraciones prácticas, pues esta forma de trabajo constituía el medio para difundir el sentido de la educación preescolar, fundar más escuelas y dar a conocer el trabajo con los menores. En 1951 se creó el Instituto para el Mejoramiento de la Situación del Niño en el Hogar y en el Jardín de Niños, el cual ofrecía Al personal docente y madres de familia conferencias por parte de especialistas sobre diversos temas vinculados al trabajo con los preescolares (SEP, 1990).

En el ámbito de la formación inicial de docentes para educación preescolar, en 1939, la carrera se amplió a seis años de estudio con el afán de fortalecer la preparación específica para el trabajar en este nivel educativo. La carrera comprendía tres años de secundaria y tres de especialización en educación con preescolares. El énfasis estuvo puesto en el conocimiento de la niñez y sus manifestaciones en el aula o en la escuela, no así en la vinculación con la comunidad. Los acercamientos de docentes con padres o madres de familia del alumnado que asistía a la escuela, tenían lugar en el ejercicio de la profesión y escasamente en la formación inicial de docentes.

En el periodo de 1952 a 1958 factores como el deterioro económico del país, la pobreza y los procesos de industrialización demandaron un mayor número de mujeres para su incorporación al mundo laboral, a su vez, las madres reclamaron espacios para la atención educativa de sus hijas e hijos. Galván (2002) documenta que con la cooperación de autoridades, sociedades de madres de familia y educadoras los planteles aumentaron en ese periodo a 1132 en todo el país; no obstante, la cobertura nacional de este servicio educativo en 1958 fue de tan solo el 8.6 por ciento (SEP, 1990).

En términos sociales, el personal docente en servicio tuvo una participación más activa con las madres mediante la creación de clubes que tenían como finalidad contribuir al mejoramiento del presupuesto familiar. En estos se procuró que las madres confeccionaran el vestido familiar y fortalecieran la práctica del ahorro familiar. Conjuntamente, docentes de educación preescolar y madres de familia fomentaron el establecimiento de roperos infantiles y de costureros comunales (SEP, 1990). 
En este contexto, el trabajo del profesorado implicó conocer las condiciones económicas y sociales de sus alumnos con miras a extender su labor educativa hacia el hogar. Con la ayuda de la Sociedad de Madres y de la comunidad en general pusieron en marcha actividades educativas orientadas a la alimentación y vestido en las familias (SEP, 1990). De nueva cuenta, se aprecia que el personal docente en servicio mantenía como un rasgo distintivo, la función social de la profesión al atender y trabajar en conjunto con padres y madres de familia; en tanto que la formación inicial de docentes se centró en el diseño de planes de estudio que ganaron terreno en el conocimiento científico y en la formación especializada para el nivel educativo.

La creciente labor social del profesorado en servicio y el trabajo con niños y niñas en edad de cursar la educación preescolar, demandó el fortalecimiento de la formación inicial de docentes y la creación de una institución especializada en la formación de docentes para los jardines de niños. El 15 de octubre de 1947 se decretó la creación de la Escuela Nacional para Maestras de Jardines de Niños (ENMJN), la operación de esta institución educativa tuvo lugar en 1948 en las instalaciones de la Escuela Nacional de Maestros y en 1960 se inauguraron las instalaciones que actualmente ocupa junto con su Laboratorio Pedagógico, Jardín de Niños Lauro Aguirre.

A principios de la década de los años setenta, la educación preescolar no estaba al alcance de la población rural, indígena ni urbana en zonas marginadas, fue a finales de esta década cuando surgieron diferentes modalidades y tipos de jardines de niños, entre ellos: jardines estancia, jardines especializados para infantes con problemas de diversa índole y jardines con modalidad extraescolar que prestaban atención a la población infantil indígena monolingüe. De igual manera, en esta década, proliferaron los jardines unitarios donde la educadora, además de atender a su grupo, tenía "que realizar las funciones de directora comisionada, encargada del jardín de niños y de conserje; y todo esto con el salario de educadora" (Bertely, 1987, p.5), situación semejante a la presentada por los y las docentes de primaria en escuelas multigrado y aún presente en el siglo XXI (Montaño, 2015).

En la década de los setenta del siglo XX, las maestras continuaron impartiendo "clases de pequeñas industrias y artesanías a las madres de familia a fin de capacitarlas para que pudieran incorporarse al proceso productivo y percibir un ingreso" (SEP, 1990, p.199). Los padres y madres de familia aportaron "cuotas voluntarias mensuales" para el mantenimiento de las escuelas (Mondragón, 2001). En este sentido, destaca la labor social del profesorado 
y la participación de padres y madres del alumnado como una constante en la historia de la educación preescolar.

Así, se identifica que en la vida cotidiana de los jardines de niños mediaba la acción pedagógica y social del personal docente para enfrentar esas realidades sociales, económicas, culturales y políticas según los contextos en que desarrollaban su ejercicio profesional, mediación vinculada al trabajo con padres y madres de familia. Es necesario distinguir que la formación inicial de docentes se caracterizó por reformas curriculares que, en la década de los años setenta, tenían como principal preocupación que el estudiantado obtuviera simultáneamente el título de profesor o profesora de primaria o preescolar y a la vez el certificado de bachillerato. Ante esta preocupación, los planes de estudio que estuvieron vigentes en esa década fueron tres: el Plan 1972, el Plan 1975 y el Plan 1975 reestructurado, en ellos se disminuyeron los espacios curriculares para la formación específica a fin de dar mayor peso a las materias científicas. Por ejemplo, el plan de estudios de 1972 de la ENMJN contempló 8 semestres que en total comprendían el estudio de 111 materias, solo una en octavo semestre, referida al estudio del desarrollo de la comunidad.

EI P72 fue reestructurado, en tanto que presentaba una fuerte carga curricular con una débil formación pedagógica (Reyes y Zúñiga, 1994). Aun estando vigente el P72, se implantó el plan de estudios 1975 (P75) que proponía brindar a la persona estudiante una formación para la docencia y estudiar a la vez el bachillerato. El P75 resultó con mayor peso curricular en la dimensión científica y humanística, tres años después fue reestructurado para reforzar el área pedagógico-psicológica.

El plan de estudios 1975 reestructurado (P75R), de Educación Normal preescolar comprendió un total de setenta y cuatro materias que cubrían el bachillerato y la formación profesional de docentes para educación preescolar. Este plan incorporó del tercer al octavo semestres la asignatura de Didáctica especial y Práctica docente como un espacio de acercamiento al ejercicio de la profesión en instituciones de educación preescolar (SEP, 1978). En términos del acercamiento del estudiantado a las condiciones en que se ejerce el trabajo docente, el P75R otorgó un peso importante a las prácticas en escuelas para población maternal y preescolar. La formación social del futuro profesorado, en el P75R, se planteó en términos de una "amplia proyección social de la docencia". Espacios curriculares como el Seminario de elaboración del informe recepcional I y II y el Seminario de desarrollo 
de la comunidad I y II enfatizaron la importancia de que el futuro maestro valorara su participación como promotor social en el desarrollo de la comunidad (SEP, 1978).

\section{Formar profesionales de la educación preescolar, la obligatoriedad del preescolar y la participación de los padres y madres de familia en las escuelas}

El crecimiento y la heterogeneidad en los servicios de educación preescolar durante la década de los setenta, recrudecieron problemas recurrentes en este nivel educativo como la falta de presupuesto, el debate entre la función pedagógica o asistencial que debería cumplir la educación preescolar y la insuficiencia de personal docente, así como de escuelas. Ante la falta de docentes, ingresaron, al servicio, recién egresadas y egresados de las Escuelas Normales que no estaban laborando debido a la escasez de plazas de nueva creación, se diseñaron programas para la formación de técnicos en educación preescolar, el programa de madres jardineras y el proyecto de educadoras comunitarias. Además, se capacitaron a maestros y maestras de educación primaria que, para 1982, sumaron cerca de cinco mil docentes (SEP, 1990).

En el ámbito de la formación inicial de docentes, el 23 de marzo de 1984 se publicó el Acuerdo mediante el cual la Educación Normal en su nivel inicial y en cualquiera de sus tipos y especialidades tendría el grado de licenciatura. En septiembre del mismo año se dio a conocer el Plan de Estudios 1984 (P84) que entró en vigor en el ciclo escolar 1984-1985. En opinión de Arnaut (2004, p.24) esta reforma "contó con un débil consenso por parte del magisterio y de las comunidades normalistas", además de implementarse en un momento en que el país enfrentaba una crisis económica muy fuerte. Este plan de estudios para la formación de licenciados y licenciadas en educación preescolar comprendía sesenta y cinco asignaturas organizadas en cursos, laboratorios, seminarios y prácticas de observación.

En cuanto a la relevancia de las prácticas de los futuros maestros, estudios etnográficos documentan que, en las escuelas primarias, las prácticas de mayor estancia con el P84 eran de una semana antes de concluir séptimo y octavo semestres (Rodríguez, 2015). Ese tiempo, según reporta otro estudio realizado por Hilario, era valorado por estudiantes de la Normal como "insuficiente para conocer los procesos que involucra el trabajo docente" (2011, p.184). En contrapeso, la línea de formación social del licenciado (a) en educación preescolar tenía como propósito fomentar, en la futura persona docente, "su participación por 
medio del ejercicio profesional en la resolución de problemas que afectan la comunidad". (SEP, 1990, p. 49), cursos como Comunidad y desarrollo destacaban el papel social del docente como promotor del cambio en las comunidades, planteamiento semejante al expresado en el P75R.

En la década de los noventa, señala Latapí (1998, p.417), con la firma del Acuerdo Nacional para la Modernización de la Educación Básica (ANMEB, 1992) en México, se “inauguró una etapa claramente diferenciada en la historia de la educación nacional”. En el plano internacional, se planteó la urgencia de garantizar el acceso universal a la enseñanza básica, profesionalizar al magisterio, impulsar la participación social, incrementar el presupuesto a la educación, descentralizar el sistema educativo, implementar reformas curriculares y procesos de evaluación a alumnos y docentes. Estas aspiraciones se vieron concretadas en la Ley General de Educación de 1993 (LGE93), en esta se estableció que el nivel preescolar junto con primaria y secundaria integrarían la educación básica de diez años: uno de preescolar, seis de primaria y tres de secundaria.

La educación preescolar no tuvo el carácter obligatorio como la primaria y la secundaria, tampoco contó con el apoyo financiero suficiente ni con docentes para atender la demanda de las familias por este servicio educativo. La nueva Ley General de Educación (1993) también planteó la constitución de órganos de participación social configurados desde la escuela y nombrados como Consejos de Participación Social, en su integración se estableció la participación de representantes de la escuela y miembros de la comunidad. Estos Consejos estarían orientados a la búsqueda de la calidad, la participación de la sociedad y la equidad educativa. Este planteamiento representa el punto de quiebre en la función social del profesorado de educación preescolar. En opinión de lbarrola, los Consejos de Participación Social impulsaron, "más bien la corresponsabilidad de la comunidad hacia las actividades formativas de la escuela, y no se mencionan ya las actividades de los maestros, desde las escuelas para impulsar el desarrollo de las comunidades" (1998, p.239).

Si bien, la declaratoria para la conformación de Consejos de Participación Social estuvo presente en documentos oficiales, la vinculación entre docentes y familias de nueva cuenta, garantizaron la continuidad de la educación preescolar y su expansión (Bertely, 1987). La participación de ambos propició que en 1990 se encontraran inscritos 2734054 infantes, 155 por ciento más que en 1980 como se muestra en la Tabla 1. 
Tabla 1. México: Evolución de la matrícula en educación preescolar de 1930 - 1990 e incremento

\begin{tabular}{ccc}
\multicolumn{3}{c}{ porcentual por década } \\
\hline Década & Alumnos inscritos (matrícula) & \multicolumn{1}{l}{ Incremento Porcentual } \\
\cline { 2 - 3 } & 17426 & - \\
$\mathbf{1 9 3 0}$ & 33848 & 94 \\
$\mathbf{1 9 4 0}$ & 115378 & 241 \\
$\mathbf{1 9 5 0}$ & 230164 & 99 \\
$\mathbf{1 9 6 0}$ & 400138 & 74 \\
$\mathbf{1 9 8 0}$ & 1071619 & 168 \\
$\mathbf{1 9 9 0}$ & 2734054 & 155 \\
\hline
\end{tabular}

Fuente: Elaboración propia, con datos proporcionados en Ornelas (1998, p.210) y Arnaut (2004, p.13).

La evolución de la matrícula en educación preescolar creció a ritmos importantes a partir de los años ochenta y noventa del siglo pasado, como se observa en la Tabla 1. Esta situación estuvo asociada al incremento poblacional y el surgimiento de diversas modalidades para la atención educativa de niños y niñas de tres a cinco años de edad. Esta tendencia continuó en las décadas subsiguientes debido, en gran parte, al lugar que ocuparía la educación preescolar en la agenda educativa del país.

Habrían de pasar casi diez años con respecto a la LGE93 para que las escuelas de educación preescolar formaran parte de la educación básica obligatoria del país. La declaratoria de obligatoriedad en el año 2002 fue calificada como una acción precipitada del Gobierno Federal, discusiones sobre el carácter educativo de este nivel, la escasa vinculación con la educación primaria, la falta de escuelas, los recursos económicos insuficientes para su operación y la formación de docentes se develaban como asuntos pendientes (Bertely, 2003; Delgado, 2003). No obstante, se estableció la obligatoriedad del nivel educativo. El decreto del 12 de noviembre del 2002 estableció los plazos para la universalización de la educación preescolar: ciclo escolar 2004-2005 para tercer grado (cinco años de edad cumplidos), 2005-2006 para segundo grado (cuatro años de edad cumplidos) y 2008-2009 primer grado (tres años de edad cumplidos). Al respecto, al interior de la SEP se escucharon declaraciones que advertían sobre la posibilidad de dejar fuera del sistema educativo nacional a la niñez de tres a cinco años de edad.

[...] el espíritu de la reforma (del artículo tercero constitucional) es la escolarización, pero la realidad es que no nos damos abasto. Si nos inclinamos por escolarizar todo el preescolar y no alcanzamos a cubrir las metas lo más probable es que vamos a condenar a muchos niños a que se queden sin escuela. (La Jornada, 2003, párr. 6) 
Efectivamente, la falta de recursos para hacer posibles tres años de educación preescolar llevaría a las autoridades educativas a reconocer, en el año 2008, que la integración a los grados de primero y segundo serían progresivos. Actualmente el tercer grado de preescolar es requisito de ingreso a la primaria. La decisión de hacer obligatoria la educación preescolar fue tomada precipitadamente y sin criterios de equidad y sensibilidad para reconocer las diferencias nacionales, en palabras de Narro, Martuscelli y Barzana (citados por Marín, 2012, párr. 8) esta decisión gubernamental "deja en deuda la responsabilidad social de justicia" para mucho de la niñez del país. Los problemas de rezago educativo, en educación preescolar, según los autores, se agravaron con la obligatoriedad y con ello la inequidad, entendida como las "diferencias en las oportunidades de ingreso, permanencia, egreso y aprendizaje dentro del sistema educativo" (Schmelkes, 1998, p. 174). En el ciclo escolar 2002-2003, había 6.5 millones de infantes de tres a seis años de edad, es decir, solo el 55 por ciento recibía atención educativa.

La cobertura por edades se concentró en los infantes de cinco años (81.4 por ciento), de la población con cuatro años de edad solo el 63.2 por ciento acudía a la escuela y el 20.6 por ciento de la niñez con tres años de edad. Para el ciclo escolar 2011-2012, el 82.2 por ciento de la población preescolar en la cohorte de edad de tres a cinco años asistía a las escuelas de educación preescolar. La atención a la población de tres años fue del 46.5 por ciento (Schmelkes, 1998). En el siguiente ciclo escolar (2012-2013), el 60 por ciento de la niñez de 3 años de edad (1.3 millones) no se inscribió a preescolar (INEE, 2014). Las desigualdades en este nivel educativo también se expresan según las subpoblaciones, por ejemplo la tasa de asistencia de la niñez que residen en hogares clasificados como "no pobres" es de $79.6 \%$, y entre la población de padres con educación superior, asciende a 82.7\%. Otra de las inequidades en el nivel de educación preescolar refiere a la atención educativa de la población indígena de tres a diecisiete años en las áreas urbanas (localidades de 2500 habitantes o más) donde la infraestructura y los servicios públicos no se han traducido "en mayores oportunidades para el acceso de estos niños a las escuelas" (INEE, 2014, p. 23).

[...] en el ciclo escolar 2012-2013, el 43.4\% (1.7 millones) del total de niños indígenas del país residió en áreas urbanas, más de la mitad (55.3\%) se ubicó en grandes ciudades de 15 mil habitantes o más, y solo $77.7 \%$ de estos niños asistió a la escuela 
(...) El caso de los alumnos monolingües es particularmente alarmante: uno de cada dos de quienes viven en zonas urbanas no asiste a la escuela. (INEE, 2014, p. 27)

Los datos presentados muestran fuertes diferencias en las oportunidades de ingreso a la educación preescolar según la edad y los grupos poblaciones. Se observa que los niños y niñas indígenas tienen menores posibilidades de acceso a las escuelas por la falta de materiales y de docentes que hablen lengua indígena. Si bien, las políticas educativas plantean metas de atención para la educación preescolar, en los hechos se aprecia que las condiciones de inequidad se acentúan. En este sentido, se podría decir que la cobertura de servicios educativos para los menores de tres a cinco años de edad ha sido una tarea pendiente en el desarrollo histórico de la educación preescolar, misma que se agrava con la declaratoria de obligatoriedad. En el informe La educación obligatoria en México, publicado por el Instituto Nacional de Evaluación Educativa (2017), señala que si bien se ha avanzado en la atención educativa a niños y niñas en edad de cursar la educación preescolar (85.7\% en el ciclo escolar 2015-2016), se continúa enfrentando problemas serios en cuanto a infraestructura escolar y personal docente con formación profesional para atender este nivel educativo.

Los análisis presentados muestran los efectos en el sector educativo de las crisis económicas recurrentes en el desarrollo histórico de México. En esas crisis, se evidencia que la presencia y participación de padres y madres de familia hacen posible el sostenimiento de las escuelas (Mercado, 1995; Mercado y Montaño, 2015), más allá de la conformación de Consejos para la Participación Social. Educadoras, padres y madres de familia asumen tareas que el Estado no resuelve, como es dotar a las escuelas del presupuesto necesario para su operación, así como de materiales y recursos para la enseñanza; una plantilla de docentes completa por escuela, personal de apoyo que mantenga limpios y en buen estado los espacios, equipos y mobiliarios para los quehaceres escolares del alumnado; y garantizar los servicios básicos como agua, luz y drenaje.

En relación con la creación de los Consejos Escolares de Participación Social, los estudios de Zurita (2008 y 2010) muestran que la política de participación social en las escuelas de educación básica ha permeado discursivamente. En docentes y directivos están presentes sentimientos de desconfianza, temor y rechazo (Zurita, 2008) hacia la participación de los padres. Su estudio revela que directivos escolares prefieren mantener a padres y 
madres de familia alejados del personal docente para evitar conflictos; en contraposición los progenitores del alumnado expresan la necesidad de estar informados y capacitados para intervenir en asuntos diversos de la escuela.

Otro de los hallazgos del estudio de Zurita, revela que padres y madres de familia son llamados por docentes para participar en actividades para la mejora de la infraestructura, para sus aportaciones monetarias o la organización de eventos para conseguir recursos económicos que permitan solventar gastos básicos para la operación de la escuela. En un estudio posterior, Zurita (2010) plantea que la Asociación de Padres de Familia es la forma de organización que privilegia la participación de padres y madres en actividades escolares. Esta política para la participación de padres y madres de familia en las escuelas trastocó el sentido de la función social de la escuela y centró la mirada en esquemas de gestión que distancian a los docentes de su participación con la comunidad.

En el ámbito de la formación inicial de maestros el ANMEB también planteó cambios en la vida académica y organizativa de las Escuelas Normales, los cuales fueron recuperados en el Programa para la Transformación y el Fortalecimiento Académicos de las Escuelas Normales (PTFAEN, 1996). Entre sus líneas de acción se encuentra la reforma curricular en el subsistema de formación docente. La entrada en vigor de los nuevos planes de estudio fue de manera escalonada, 1997 para la licenciatura en Educación Primaria; 1999 las licenciaturas en Educación Preescolar y Educación Secundaria; 2002 la licenciatura en Educación Física y en el 2004 la licenciatura en Educación Especial. Estos planes establecían en sus documentos un modelo de profesional enseñante con capacidad de observar, reflexionar y analizar su propia práctica pedagógica para resolver dificultades, valorar aciertos y trabajar en torno a retos que presenta el trabajo docente. De acuerdo con la orientación de esta reforma, la formación en la práctica tuvo como propósito:

[...] asegurar que los procesos de formación de nuevos profesores tomen en consideración las formas de trabajo, las propuestas pedagógicas, los recursos y materiales educativos que se usan y aplican en los planteles de educación preescolar; así como las condiciones en las que trabajan y los problemas que enfrentan los maestros. (SEP, 1999, p. 22)

En esta perspectiva, se acercó gradualmente a los futuros docentes a las culturas escolares y a los contextos sociales donde ejercerían su profesión. No obstante, las 
relaciones familia escuela y escuela familia escasamente se abordaron en la formación inicial para la docencia. Situaciones que a la fecha propician en el profesorado principiante que el trabajo con padres y madres sea referido como un momento difícil, en tanto que implica conocerlos y aprender a tratarlos.

En la reforma curricular a la Educación Normal iniciada en la década de los noventa, se reconoció que el aprendizaje de la docencia ocurre de manera importante en la práctica y en las condiciones reales de la vida escolar. Czarny (2003), Estrada (2009), Hilario (2011), Mercado (1997), Rodríguez (2015) y Villegas (2006), en sus estudios etnográficos enfocados en los procesos para la formación inicial de docentes en educación primaria, Plan de estudios 1997, documentan la relevancia de la formación en la práctica para estudiantes y formadores de docentes en las Escuelas Normales, ambos valoran - como muestran los estudios - los periodos de práctica en escuelas de educación básica (preservicio) como espacios formativos para el desempeño docente. Particularmente, los estudios de Estrada (2009), Hilario (2011), Mercado (1997) y Rodríguez (2015) recuperan voces de estudiantes que refieren a la relación docente con padres y madres de familia. En estas investigaciones se muestra que, en el preservicio el estudiantado normalista reconoce la importancia del contacto con los padres y madres de familia y su intervención en las escuelas. Al respecto, Estrada $(2009$, p. 85$)$ documenta que las y los futuros maestros aprenden "a valorar la importancia que los padres de familia tienen en la educación escolar de sus hijos", a tomarlos en cuenta como "un elemento más de las actividades docentes" y al "planificar sus actividades considerando a esos participantes de la vida escolar". La población estudiantil normalista, plantea el autor, también se dan cuenta de la fuerte injerencia de los padres y madres del alumnado en las escuelas y logran identificar que ellos "están presentes y vigilantes de las actividades que los profesores realizan -o no- en el aula; principalmente de aquellas acciones que ejercen sobre sus hijos" (2009, p. 86).

El estudio ya referido de Rodríguez muestra la relevancia que tanto asesores como estudiantes de la Normal le otorgan a las prácticas de preservicio en el P97. Los asesores destacan como "ventaja" el conocimiento que el futuro profesorado construye sobre "las condiciones reales en que el trabajo docente se desarrolla y las diversas actividades que involucran a maestros, padres de familia y alumnos" (2015, p. 117).

Por ese medio, las prácticas de preservicio, futuras personas docentes reconocen haberse acercado a las condiciones reales del trabajo docente y aprender de sus tutores, 
alumnado y familias, no sin conflictos y diferencias durante el proceso. El lugar sustancial que se le otorgó en estos planes de estudio a la formación práctica en el medio escolar, la duración prolongada de éstas, el acompañamiento de maestros más experimentados y los seminarios de análisis del trabajo docente configuran espacios que algunos autores han destacado como importantes para la "construcción de una base de conocimientos sobre las condiciones que definen el acto de enseñar en el medio escolar y, más específicamente, en la clase" (Tardif, Figueroa, Cividini y Mujawamaruya, 2000, p. 53).

Si bien, la reforma curricular en las Escuelas Normales de la década de los noventa buscó fortalecer la formación en la práctica del futuro profesorado, la implementación de un nuevo Plan y programas de estudios para la formación de docentes de preescolar y primaria en el año 2012, sin el consenso del profesorado normalistas (Mercado, 2010 y Sandoval, 2011), se caracterizó por la ausencia de materiales y recursos para operar la reforma, así como la escasa presencia de espacios para la actualización de los formadores de docentes.

Destaca de este plan de estudios la reducción a un semestre del espacio para las prácticas profesionales en comparación con los planes de estudio de la década de los noventa. Este no es un asunto menor, dado el significado que tienen para la formación del futuro profesorado, las prácticas de preservicio en las escuelas de educación básica. Experiencias formativas que no son equiparables con los análisis de casos de enseñanza, de incidentes críticos, ni con la resolución hipotética de problemas de enseñanza, la elaboración de proyectos o propuestas pedagógicas que propone el Plan de estudios 2012 como estrategias de aprendizaje auténtico para estudiantes normalistas.

En palabras de Latapí (2003, p.18), "Ios maestros aprenden principalmente de su práctica diaria”, la formación inicial de docentes no está exenta de ello. En este sentido, resultan necesarios estudios que analicen, a profundidad, las implicaciones formativas de una malla curricular que prioriza en el último año de formación solo un semestre para prácticas profesionales intensivas. Del mismo modo, se requiere documentar, según el planteamiento del Plan de estudios 2012, cómo viven las y los futuros profesionales de la educación sus acercamientos al trabajo con padres de familia, ya sea mediante prácticas de observación y entrevista en los primeros semestres o en el diseño y desarrollo de propuestas socioeducativas que pretenden orientar acciones dirigidas a padres de familia o miembros de la comunidad. Ya se ha hecho mención de que uno de los problemas más frecuentes en los primeros años de ejercicio docente refiere a las relaciones de los docentes principiantes con 
padres y madres de familia (INEE, 2017). Los encuentros del profesorado con padres y madres de los preescolares que asisten a los jardines de niños, al igual que en otros niveles educativos, demandan al personal docente un conocimiento profesional. La ausencia 0 escasa presencia de contenidos en los planes de estudio para la formación inicial sobre el tema de las relaciones entre la escuela y las familias omite una dimensión del trabajo docente presente en toda escuela de educación básica.

\section{A manera de cierre}

En etnografía, comprender las transformaciones educativas implica una mayor profundidad en la comprensión histórica de las escuelas actuales y una mayor sensibilidad etnográfica en el estudio del pasado (Rockwell, 2009, p. 150). A lo largo del texto, se plantearon elementos de orden social, político y económico para comprender, a grandes rasgos, el por qué y para qué del trabajo docente del profesorado de educación preescolar con los padres y madres de familia. El recuento es un ejercicio no acabado que permite reconocer que la educación preescolar en México, desde sus orígenes, ha sido un nivel educativo afectado recurrentemente por la ausencia de financiamiento o por los recortes presupuestales que privilegian el fortalecimiento de otros niveles educativos como son la educación primaria o secundaria.

La creación de la educación preescolar encontró, en el profesorado en servicio y en el trabajo, principalmente con padres y madres de familia, el medio que posibilitó la expansión del servicio educativo y el incremento en la cobertura a nivel nacional. La revisión de diversos documentos oficiales e investigaciones, principalmente etnográficas, permitió corroborar que los saberes docentes en torno al trabajo con padres y madres de familia toma lugar en el ejercicio cotidiano de la práctica, en el hacer día a día, en los momentos de conflicto o de dialogo con los padres y en el desarrollo conjunto de acciones en beneficio de la comunidad y del alumnado en la escuela.

El breve recuento histórico permite subrayar que, durante un siglo, las educadoras y docentes en servicio otorgaron un significado social al trabajo con los padres y/o madres de sus alumnos, dirigido a generar mejores condiciones para las escuelas existentes, la creación de nuevos jardines de niños y el mantenimiento de estos en momentos de fuertes crisis económicas. De igual forma, generaron acciones para hacer del trabajo en el aula un espacio para detectar necesidades de las familias. 
Este hacer de las maestras y maestros en servicio no remite a prácticas empíricas, la capacidad organizativa y la visión del personal docente propiciaron la generación de espacios en diversas instituciones para la formación específica en el nivel preescolar, que contempló el trabajo con las familias. Así, ganaron presencia los clubs, talleres y reuniones con mujeres para fomentar el ahorro, el cuidado y alimentación familiar. Del mismo modo, profesorado de educación preescolar y miembros de la comunidad organizaron actividades recreativas y culturales para reunir recursos económicos, en apoyo, a la creación de escuelas para niños y niñas en edad de cursar el preescolar o para el mantenimiento de los jardínes de niños existentes. Se podría decir que la concepción de la educación preescolar estaba estrechamente vinculada a las madres por su tarea educativa con sus hijas e hijos, pero también a una visión de lo educativo que intentaba renovarse ante los avances del pensamiento pedagógico y de la ciencia. Esta situación, para las maestras en servicio, implicó construir conocimientos y habilidades para trabajar con comunidades diversas, procesos de los cuales se conoce muy poco.

En cambio, la formación inicial docente se centró en la lógica de formar personas profesionales centradas en conocer a la niñez en sus contextos reales. De esta forma, los espacios curriculares destinados a la observación de la práctica docente representaron, para docentes en formación, el encuentro con experiencias formativas que les brindaron elementos para conocer, entre otras cosas, los contextos sociales y familiares de la población infantil, construir conocimientos sobre cómo relacionarse con padres y madres en asuntos vinculados al quehacer escolar del estudiantado, así como en la organización y funcionamiento de las escuelas. Cabe destacar los hallazgos en las investigaciones de Estrada (2009), Hilario (2011) y Rodríguez (2015) referentes a las prácticas profesionales en la formación inicial evidencian que estos espacios formativos permiten al estudiantado la construcción de saberes iniciales en torno al trabajo docente, algunos, referidos a las relaciones con padres y madres de familia.

En este sentido, es preciso revisar y discutir por qué en la formación inicial de docentes no se abren espacios curriculares para el estudio del trabajo con la comunidad. En opinión de Loughran (2008), los maestros deben estar preparados para trabajar con la diversidad de padres y madres de familia o cuidadores de los menores que asisten a las escuelas y proveerse de las competencias y habilidades necesarias. Martorell (2016), Mercado y Montaño (2015), Osorio (2014) y Palos, Ávalos, Flores y Montes (2017), destacan por 
ejemplo, la importancia de la comunicación permanente con padres y madres de familia para mejorar los procesos pedagógicos que orientan la enseñanza en este nivel educativo.

En los procesos para la formación inicial del profesorado es de vital importancia propiciar discusiones diversas en torno al estudio de las relaciones escuela comunidad. Algunas de éstas podrían versar sobre el papel que ocupan las familias, según sus contextos, en los procesos de aprendizaje de los niños y niñas preescolares. De igual forma, conocer y analizar las concepciones de formadores de docentes respecto al trabajo del profesorado con padres y madres de familia. Otra línea temática alude a los procesos de gestión que implican el trabajo conjunto del profesorado con los miembros de la comunidad, particularmente con padres y madres de familia a fin de mejorar el funcionamiento de la escuela.

Un ejercicio necesario en las escuelas formadoras de docentes remite a la construcción de procesos para el acompañamiento a su estudiantado para el desarrollo o fortalecimiento de competencias en el trabajo con padres y madres de familia, por ejemplo, mediante talleres con temáticas específicas que propicien el desarrollo de herramientas para el trabajo cotidiano en las escuelas.

Estos y otros temas emergentes estarán puestos en las discusiones relativas a la formación de docentes. En términos de procesos de investigación, es necesario desarrollar estudios sobre las percepciones que configuran las y los futuros maestros en su paso por la Normal sobre los padres y madres de familia y las experiencias en las prácticas de acercamiento al trabajo docente en escuelas de educación preescolar. De igual forma, es necesario abrir el debate y las aportaciones sobre este tema en el marco de las reformas curriculares para la formación inicial y continua de docentes, así como en la formación de los formadores de docentes. Una veta más de investigación remite a estudios que den cuenta de las expresiones que actualmente cobra la función social del profesorado en la vida cotidiana de las escuelas, frente a políticas educativas orientadas a fortalecer la participación social de padres y madres de familia mediante esquemas formales, como son los Consejos Escolares de Participación Social. 


\section{Agradecimientos}

A la Dra. Maricruz Aguilera Moreno por su lectura atenta, observaciones y comentarios a este artículo, y por su apoyo para la redacción del abstract. Al Dr. Inés Lozano Andrade por la escucha y aportaciones para la mejora del escrito. Ambos, académicos de la Escuela Normal Superior de México.

\section{Referencias}

Arnaut Salgado, Alberto. (2004). El sistema de formación de maestros en México, continuidad, reforma y cambio (Cuadernillo de discusión № 17). México: Secretaría de Educación Pública.

Bazant de Saldaña, Mílada. (1993). Historia de la educación durante el porfiriato. México: El Colegio de México.

Bazant de Saldaña, Mílada. (2002). En busca de la modernidad. Procesos educativos en el Estado de México 1873-1912. México: El Colegio Mexiquense- El Colegio de Michoacán.

Bazant de Saldaña, Mílada. (2003). Una visión educativa contrastada: La óptica de Laura Méndez de Cuenca. México: Documentos de investigación El Colegio Mexiquense A.C.

Bazant de Saldaña, Mílada. (2009). Laura Méndez de Cuenca Mujer Indómita y moderna 1853-1928, Vida cotidiana y entorno educativo. México: Biblioteca Mexiquense del Bicentenario.

Bertely Busquets, María. (1987). La educación preescolar en México/Recuento estadístico y relatos de la vida de todos los días en los jardines de niños. Revista Cero en Conducta, 2(7), 5-9.

Bertely Busquets, María. (1998). Costumbres estereotipadas en la historia de la educación preescolar en México: un reto a la calidad y descentralización educativas. Revista Cero en Conducta, $3(11$ y 12$)$, 43-52.

Bertely Busquets, María. (2003). Paradojas de la reforma al estatuto jurídico de la educación preescolar en México. Revista Educación 2001, (92), 10-17.

Campos Alba, Elida Lucila. (2013). De las escuelas de párvulos a los jardines de niños. Construcciones de la cultura escolar en la educación preescolar del Estado de México 1881-1926. Recuperado de https://docplayer.es/48295333-De-las-escuelas-deparvulos-a-los-jardines-de-ninos.html

Civera Cerecedo, Alicia. (1999). Experiencias educativas en el Estado de México. México: El Colegio Mexiquense. 
Czarny krischkautzky, Gabriela. (2003). Las Escuelas Normales frente al cambio. Un estudio de seguimiento a la aplicación del Plan de Estudios 1997 (Cuadernos de discusión N 16). México: Secretaría de Educación Pública.

De Ibarrola Nicolín, María. (1998). La formación de los profesores de educación básica en el siglo XX. En Pablo Latapí (Ed.), Un siglo de educación en México (Tomo II; pp. 230275). México: Fondo de Cultura Económica.

Delgado Ballesteros, Gabriela. (2003). Educación y género. En María Bertely Busquets (Ed.), Educación, Derechos Sociales y Equidad (Tomo II, Colección: La Investigación Educativa en México 1992-2001; pp. 467-594). México: Consejo Mexicano de Investigación Educativa.

Estrada Rodríguez, Pedro Antonio. (2009). Formación inicial en la normal: construcción de significados de maestros y estudiantes en las practicas preservicio (Tesis para optar por el grado de Doctor en Ciencias en la Especialidad de Investigaciones Educativas). Departamento de Investigaciones Educativas del Centro de Investigación y Estudios Avanzados del Instituto Politécnico Nacional, Ciudad de México, México.

Galván Lafarga, Luz Elena, Quintanilla Osorio, Susana y Ramírez González, Clara Inés (Eds.). (2003). Historiografía de la educación en México (Vol. 10; Colección: La Investigación Educativa en México 1992-2001). México: Consejo Mexicano de Investigación Educativa.

Galván Lafarga, Luz Elena. (2002). De la escuela de párvulos al preescolar. Una historia por contar. Diccionario de historia de la educación. México: Universidad Nacional Autónoma de México. Recuperado de http://biblioweb.tic.unam.mx/diccionario/htm/indart.htm

Galván Mora, Lucila. (1998). El trabajo conjunto de padres y maestros (Tesis para optar por el grado de Maestro en Ciencias en la Especialidad de Investigaciones Educativas). Departamento de Investigaciones Educativas del Centro de Investigación y Estudios Avanzados del Instituto Politécnico Nacional, Ciudad de México, México.

García Alcaráz, María Guadalupe. (2002). La participación de los padres de familia en la educación, siglo XIX y XX. Diccionario de historia de la educación. México: Universidad Nacional Autónoma de México. Recuperado de http://biblioweb.tic.unam.mx/diccionario/htm/indart.htm

Geertz James, Clifford. (1987). La interpretación de las culturas. Barcelona: Gedisa.

González, Araceli Paula. (2010). Estefanía Castañeda: un acercamiento histórico a su vida intelectual. Revista ISCEEM, (9), 15-22. Recuperado de https://issuu.com/isceem/docs/revista-9/21

Hilario Coronel, Nancy. (2011). Procesos formativos en las prácticas preservicio de estudiantes de magisterio: entre la normal y la primaria (Tesis para optar por el grado de Maestro en Ciencias en la Especialidad de Investigaciones Educativas). Departamento de Investigaciones Educativas del Centro de Investigación y Estudios Avanzados del Instituto Politécnico Nacional, Ciudad de México, México. 
Instituto Nacional de Evaluación Educativa. (2014). El derecho a una educación de calidad. Informe 2014. México: Instituto Nacional de Evaluación Educativa.

Instituto Nacional de Evaluación Educativa. (2017). La educación obligatoria en México informe. México: Instituto Nacional de Evaluación Educativa.

Larroyo, Francisco. (1947). Historia comparada de la educación en México. México: Porrúa.

Latapí Sarre, Pablo. (2003) ¿Cómo aprenden los maestros? (Cuadernos de discusión N 6). México: Secretaría de Educación Pública.

Latapí Sarre, Pablo. (1998). Perspectivas hacia el siglo XXI. En Pablo Latapí (Ed.), Un siglo de educación en México (Tomo II; pp. 417-436). México: Fondo de Cultura Económica.

Loughran, Sandra. (2008). The Importance Of Teacher/Parent Partnerships: Preparing PreService And In-Service Teachers. Journal of College Teaching \& Learning, 5(8), 35-38.

Marín, Nidia. (30 de diciembre, 2012). La mayor tarea en educación es el nivel preescolar: UNAM. El Sol de México. Recuperado de https://setebc.wordpress.com/2013/01/01/lamayor-tarea-en-educacin-es-en-nivel-preescolar-unam/

Martorell Esquivel, Karla. (2016). Saberes profesionales de docentes en educación preescolar que laboran con niñez menor de tres años de edad: un estudio en Costa Rica (Tesis para obtener el grado de doctorado). Faculté des sciences de l'éducation, Université de Montréal, Canadá. Recuperado de https://papyrus.bib.umontreal.ca/xmlui/bitstream/handle/1866/18371/Martorell Esquivel Karla 2016 these.pdf?sequence $=2 \&$ isAllowed $=y$

Meneses Morales, Ernesto. (1986). Tendencias educativas oficiales en México 1821- 1911. México: Universidad Iberoamericana.

Mercado Maldonado, Ruth y Luna Elizarrarás, María Eugenia. (2013). Saber enseñar: un trabajo de maestros. Análisis de la docencia en el aula y propuestas para mejorarla. México: somosmaestr@s.

Mercado Maldonado, Ruth y Montaño Sánchez, Leticia. (2015). Procesos de participación entre profesoras de jardines de niños y madres de familia en actividades de enseñanza. Revista Mexicana de Investigación Educativa, 20(65). Recuperado de http://www.redalyc.org/articulo.oa?id=14035408002.

Mercado Maldonado, Ruth. (1985). La educación primaria gratuita, una lucha popular cotidiana. Cuadernos de investigación educativa 17. México: Departamento de Investigaciones Educativa, Centro de Investigación y de Estudios Avanzados del Instituto Politécnico Nacional.

Mercado Maldonado, Ruth. (1997). Formar para la educacional normal. México: Secretaría de Educación Pública. 
Mercado Maldonado, Ruth. (2010). Un debate actual sobre la formación inicial de docentes en México. Revista Semestral de Associãção Brasileira de Psicologia Escolar e Eduçional, 14(1), 149-157.

México. (1993). Ley General de Educación. Recuperado de http://www.diputados.gob.mx/LeyesBiblio/ref/lge/LGE orig 13jul93 ima.pdf

Mondragón Sosa, Lidia. (2001). La educación preescolar en Chilpancingo 1929-2000, Centenaria Escuela Normal del Estado "Ignacio Manuel Altamirano". México: Guerrero.

Montaño Sánchez, Leticia. (2015). El trabajo docente en jardines de niños: relaciones de educadoras con madres de familia en la vida escolar (Tesis para optar por el grado de Doctora en Ciencias en la Especialidad de Investigaciones Educativas). Departamento de Investigaciones Educativas del Centro de Investigación y Estudios Avanzados del Instituto Politécnico Nacional, Ciudad de México, México.

Ornelas Navarro, Carlos. (1998). La cobertura de la educación básica. En Pablo Latapí (Ed.), Un siglo de educación en México (Tomo II; pp. 111-172). México: Fondo de Cultura Económica.

Osorio Sánchez, Karime (2014). La Retroalimentación Formativa en el Proceso de Enseñanza-Aprendizaje de Estudiantes en Edad Preescolar. Revista Iberoamericana de Evaluación Educativa, 7(1), 13-30.

Palos Toscano, María, Ávalos Latorre, María, Flores Escobar, Francisco y Montes Delgado, Roberto (2017). Creencias de madres y docentes sobre el aprendizaje de la lectoescritura en Educación Preescolar. Revista Actualidades Investigativas en Educación, 17(3), pp. 1-21. DOI: http://dx.doi.org/10.15517/aie.v17i3.29066

Reyes Flores, Candelario. (1948). Estefanía Castañeda. Vida y obra de una gran kindergarten. México: El lápiz rojo.

Reyes Esparza, Ramiro y Zúñiga Rodríguez, Rosa María. (1994). Diagnóstico del Subsistema de Formación Inicial. México: Fundación Sindicato Nacional de Trabajadores de la Educación (SNTE) para la cultura del maestro mexicano.

Rivas Borrel, Sonia y Urgarte Artal, Carolina. (2014). Formación docente y cultura participativa del centro educativo: claves para favorecer la participación familia-escuela. Teacher Training and a Participative Culture in Schools: Keys for Encouraging FamilySchool Partnership. Estudios sobre Educación, 27, 153-168. DOI: 10.15581/004.27.153-168.

Rockwell Richmond, Elsie. (2009). La experiencia etnográfica. Historia y cultura en los procesos educativos, Buenos Aires: Paidós.

Rodríguez Rivera, Diana. (2015). Dimensiones formativas en una normal rural: las prácticas escolares y el internado (Tesis para optar por el grado de Maestro en Ciencias en la Especialidad de Investigaciones Educativas). Departamento de Investigaciones Educativas del Centro de Investigación y Estudios Avanzados del Instituto Politécnico Nacional, Ciudad de México, México. 
Sandoval Flores, Etelvina. (2011). Maestros sin escuela. Revista Nexos. Recuperado de http://www.nexos.com.mx/?p=14273

Saucedo Ramos, Claudia, Guzmán Gómez, Carlota, Sandoval Flores, Etelvina y Galaz Fontes, Jesús (Eds.). (2013). Estudiantes, maestros y académicos en la investigación educativa. Tendencias, aportes y debates, 2002-2011 (Colección Estados del Conocimiento). México: Consejo Mexicano de Investigación Educativa.

Schmelkes del Valle, Sylvia. (1998). La educación básica. En Pablo Latapí (Ed.), Un siglo de educación en México (Tomo II; pp. 173-194). México: Fondo de Cultura Económica.

Secretaría de Educación Pública, México. (1978). Programas. Educación Normal Preescolar. Plan de estudios de Educación Normal Preescolar 1975 reestructurado. México: SEP.

Secretaría de Educación Pública, México. (1990). Educación Preescolar. México 1880-1982. México: SEP.

Secretaría de Educación Pública, México. (1999). Plan de Estudios. Licenciatura en Educación Preescolar. México: SEP.

Tardif, Maurice, Figueroa, Leoncio, Cividini, Mónica y Mujawamariya, Donatille. (2000). La formación de maestros en Europa y América del Norte según los nuevos enfoques profesionales de la enseñanza. Revista Propuesta Educativa, 10(22), 49-60.

Villegas Villarreal, Ninfa Maricela. (2006). Aprendizajes de la profesión: los futuros maestros en las prácticas pedagógicas (Tesis para optar por el grado de Maestra en Desarrollo Educativo). Universidad Pedagógica Nacional, Unidad Ajusco, Ciudad de México, México.

Zapata Cano, María Rosaura. (1946). La educación preescolar en México. México: Secretaría de educación pública.

Zea Aguilar, Leopoldo. (1956), Del liberalismo a la revolución en la educación mexicana. México: Biblioteca del Instituto Nacional de Estudios Históricos de la Revolución.

Zúñiga Núñez, Martha Alejandra. (2002). La educación preescolar, siglos XIX y XX. Diccionario de historia de la educación. México: Universidad Nacional Autónoma de México. Recuperado de http://biblioweb.tic.unam.mx/diccionario/htm/indart.htm

Zurita Rivera, Úrsula. (2008). Reflexiones en el marco de la evaluación nacional de la participación social en la educación básica 2000-2006. México: Observatorio Ciudadano de la Educación.

Zurita Rivera, Úrsula. (2010). La educación para la vida democrática a través de la participación social: puntos de encuentro entre la escuela y la familia. Revista Interamericana de Educación para la Democracia, 3(2), 51-74. 